\title{
Dexamethasone can attenuate the pulmonary inflammatory response via regulation of the IncH19/miR-324-3p cascade
}

Ye Chen ${ }^{1}$, Chao Zhang ${ }^{2,3,4,5,6}$, Chang-Xue Xiao ${ }^{2,3,4,5,6}$, Xiao-dong $\mathrm{Li}^{7}$, Zhi-li Hu${ }^{1}$, Shou-di He ${ }^{8}$, Xiao-jun Xiao ${ }^{9}$ and Feng $X^{2,3,4,5,6^{*}}$

\begin{abstract}
Objective: To investigate IncRNAs and their roles in regulating the pulmonary inflammatory response under dexamethasone (Dex) treatment.

Methods: IL-1 1 (10 ng/mL) and LPS $(1 \mu \mathrm{g} / \mathrm{mL})$ was used to construct inflammatory cell models with A549 cells; IL$1 \beta$ performed better against LPS. Different concentrations of Dex were used to attenuate the inflammation induced by IL-1 $\beta$, and its effect was assessed via RT-PCR to detect inflammatory cytokine-related mRNA levels, including those of IKK- $a$, IKK $\beta, I L-6, I L-8$, and TNF- $a$. Furthermore, ELISA was used to detect the levels of the inflammatory cytokines TNF- $a$, IL-6, and IL-8. RT-PCR was used to quantify the levels of IncRNAs, including IncMALAT1, IncHotair, InCH19, and IncNeat1. LncH19 was most closely associated with the inflammatory response, which was induced by $\mathrm{IL}-1 \beta$ and attenuated by Dex. Among the IncRNAs, the level of IncH19 showed the highest increase following treatment with 1 and $10 \mu \mathrm{M}$ Dex. Therefore, IncH19 was selected for further functional studies. LnCH19 expression was inhibited by shRNA transduced with lentivirus. Cell assays for cell proliferation and apoptosis as well as RT-PCR, western blot, and ELISA for inflammatory genes were conducted to confirm the functions of IncH19. The predicted target miRNAs of IncH19 were hsa-miR-346, hsa-miR-324-3p, hsa-miR-18a-3p, hsa-miR-18b-5p, hsa-miR-146b-3p, hsamiR-19b-3p, and hsa-miR-19a-3p. Following estimation via RT-PCR, hsa-miR-346, hsa-miR-18a-3p, and hsa-miR-324$3 p$ showed consistent patterns in A549 NC and A549 shlncH19. An miRNA inhibitor was transfected into A549 NC and A549 shlncH19 cells, and the expression levels were determined via RT-PCR. hsa-miR-324-3p was inhibited the most compared with hsa-miR-346 and hsa-miR-18a-3p and was subjected to further functional studies. RT-PCR, ELISA, and western blotting for inflammatory gene detection were conducted to validate the functions of the target hsa-miR-324-3p.
\end{abstract}

(Continued on next page)

\footnotetext{
* Correspondence: xufeng9899@163.com

2Department of Pediatric Intensive Care Unit, Children's Hospital of

Chongqing Medical University, No. 136 Zhongshan two road Yuzhong

district, Chongqing 400013, China

${ }^{3}$ Ministry of Education Key Laboratory of Child Development and Disorders,

Children's Hospital of Chongqing Medical University, Chongqing 400013,

China

Full list of author information is available at the end of the article
}

(C) The Author(s). 2021 Open Access This article is licensed under a Creative Commons Attribution 4.0 International License, which permits use, sharing, adaptation, distribution and reproduction in any medium or format, as long as you give appropriate credit to the original author(s) and the source, provide a link to the Creative Commons licence, and indicate if changes were made. The images or other third party material in this article are included in the article's Creative Commons licence, unless indicated otherwise in a credit line to the material. If material is not included in the article's Creative Commons licence and your intended use is not permitted by statutory regulation or exceeds the permitted use, you will need to obtain permission directly from the copyright holder. To view a copy of this licence, visit http://creativecommons.org/licenses/by/4.0/ The Creative Commons Public Domain Dedication waiver (http://creativecommons.org/publicdomain/zero/1.0/) applies to the data made available in this article, unless otherwise stated in a credit line to the data. 


\begin{abstract}
(Continued from previous page)
Results: Treatment with 1 and $10 \mu \mathrm{M}$ Dex could effectively attenuate the inflammatory response. During this process, IncH19 expression significantly increased $(P<0.05)$. Therefore, treatment with $1 \mu \mathrm{M}$ Dex was used for further study. Under IL-1 $\beta$ treatment with or without Dex, IncH19 inhibition led to an increase in cell proliferation; a decrease in cell apoptosis; an increase in the protein levels of inflammatory genes; phosphorylation of P65, ICAM-1, and VCAM-1; and increase inflammatory cytokines. Prediction of the targets of IncH19 and validation via RT-PCR revealed that miR-346, miR-18a-3p, and miR-324-3p negatively correlate with IncH19. Additionally, Dex increased the IncH19 expression but reduced that of the miRNAs. Among the miRNAs, miR-324-3p was the most markedly downregulated miRNA following treatment of miRNA inhibitors. The MTS assay and cell apoptosis assay showed that the miR-324-3p inhibitor inhibited cell proliferation and induced cell apoptosis, thereby significantly attenuating the inflammatory response, which reversed the effect of IncH19 in regulating cell proliferation and the secretion of inflammatory cytokines $(P<0.05)$. Therefore, IncH19 might regulate miR-324-3p in pulmonary inflammatory response under Dex treatment.
\end{abstract}

Conclusion: Dex can attenuate the pulmonary inflammatory response by regulating the IncH19/miR-324-3p cascade.

Keywords: Pulmonary, Inflammatory response, Dexamethasone, IncRNA, miRNA

\section{Introduction}

Pulmonary inflammatory defense is initiating by mobilizing inflammatory cells and phlogistic factors into the lung [1]. Airway epithelial cells activation is the first line of defense for airway and lung from inflammation [2]. Epithelial cells recognize microorganisms via toll-like receptors; activate the NF- $\mathrm{BB}$ signaling pathway; and increase airway epithelial inflammatory cytokines, such as IL-8, IL-1 $\alpha$, and tumor necrosis factor- $\alpha$ (TNF- $\alpha)$ [3]. However, immune imbalance caused by excessive or chronic inflammation can lead to a variety of lung diseases, including asthma, acute lung injury and diffuse interstitial disease [4]. Inflammatory cytokines are involved in inducing, prolonging, and amplifying the inflammatory response; inducing airway hyperresponsiveness by promoting the growth, proliferation and differentiation of eosinophils, and promoting the generation of allergy-specific immunoglobulin E. Wilson. found that some of the therapeutic efficacy of inhaled corticosteroids is mediated via the inhibition of NF-kB-regulated gene expression [5]. NF- $\mathrm{kB}$ is a transcription factor that regulates several cytokine and adhesion molecule genes expressed during allergic inflammation, including colony-stimulating factor, TNF- $\alpha$, intercellular adhesion molecule (ICAM)-1, and vascular cell adhesionmolecule-1 (VCAM-1) [5]. Dexamethasone (Dex) is a synthetic glucocorticoid that exerts anti-inflammatory effects by inhibiting the NF- $\mathrm{kB}$ signaling pathway [6]. However, the molecular mechanism of Dex in pulmonary inflammatory diseases remains unclear.

Long non-coding RNAs (lncRNAs) are involved in several biological processes, including cell growth, cell differentiation, and the cell cycle as well as in the progression and metastasis of cancer [7, 8]. Researchers have suggested that inflammatory cytokines, particularly $\mathrm{NF}-\mathrm{kB}$, play critical roles in regulating lncRNAs in human diseases [9]. miR-489 targets CHRF to inhibit MyD88 and Smad expression in pulmonary fibrosis [10].
In addition, in patients with COPD, differentially expressed NEAT1 correlated with increased inflammation [11]. Protein phosphatase $\varepsilon$ (PTPRE) is involved in accelerating pulmonary allergic inflammation [12]. Therefore, we hypothesized that specific IncRNAs regulate the pathological processes underlying pulmonary inflammation.

In this study, we targeted specific lncRNAs that have been reported to be correlated with the inflammatory response in order to characterize their mechanistic roles in lung inflammatory diseases. The inflammatory response was induced via IL-1 $\beta$ and LPS using previously described methods in A549 cells [13-15] and was then attenuated using Dex. We quantified the changes in lncRNA expression during IL-1 $\beta$ and Dex treatment in A549 cells. In addition, we determined the functional roles of candidate lncRNAs in regulating the inflammatory response under Dex treatment in a pulmonary inflammation cell model. Because the functions of lncRNAs are usually performed by targeting miRNAs, we identified the miRNA targets of lncRNAs as well as quantified their expression levels to characterize their functions.

\section{Materials and methods}

\section{Cell culture and treatment}

A549 were obtained from Shanghai Cell Bank (Shanghai, China) and were cultured at $37{ }^{\circ} \mathrm{C}$ with $5 \% \mathrm{CO}_{2}$. Cells were maintained on high-glucose DMEM supplemented with $10 \%$ fetal bovine serum (Gibco, USA). Cells were cultured, amplified, and passaged. After 3 days, cells were digested and pelleted via centrifugation. Cells morphology was observed using a light microscope and suspended at a concentration of $1 \times 10^{6} / \mathrm{mL}$. For constructing the inflammatory cell model, $10 \mathrm{ng} / \mathrm{mL}$ IL-1 $\beta$ (Peprotech, USA) or $1 \mu \mathrm{g} / \mathrm{mL}$ LPS (Sigma, USA) was added and incubated for 8,16 , and $24 \mathrm{~h}$. To determine 
the effect of Dex (Sigma), different concentration of Dex $(10 \mathrm{nM}, 100 \mathrm{nM}, 1000 \mathrm{nM}$, and $10,000 \mathrm{nM})$ and $10 \mathrm{ng} /$ $\mathrm{mL}$ IL-1 $\beta$ were added at the same time and the cells were incubated for $24 \mathrm{~h}$. To assess the functions of lncH19 and miR-324-3p, $10 \mathrm{ng} / \mathrm{mL}$ IL-1 $\beta$ and $1 \mu \mathrm{M}$ Dex were simultaneously added and the cells and supernatants were harvested for further studies.

\section{MTS assay}

Cells were suspended at a density of $1 \times 10^{6} / \mathrm{mL}$ and were seeded into 96 -well plates with $100 \mu \mathrm{L}$ per well. Then, $10 \mathrm{ng} / \mathrm{mL}$ IL- $1 \beta$ was added to the cells with or without Dex $(1 \mu \mathrm{M})$ for $24 \mathrm{~h}$ following transfection with or without an miRNA inhibitor for $24 \mathrm{~h}$. Cells were examined at 1, 2, and 3 days. MTS was added, and after 3 $h$ of incubation, the optical density of the cells was detected at $490 \mathrm{~nm}$.

\section{Cell apoptosis assay}

Cells at a density of $5 \times 10^{5}$ cells/well were seeded into 6-well plates overnight at $37^{\circ} \mathrm{C}$. After treatment, cells were then pelleted and washed with PBS. The cells were resuspended in $1 \times$ binding buffer, followed by the addition of $5 \mu \mathrm{L}$ of $7-\mathrm{AAD}$ staining solution and $5 \mu \mathrm{L}$ of APC-conjugated Annexin V. Samples were tested using the FACS Calibur flow cytometer. The percentage of apoptotic cells was determined.

\section{Lentivirus preparation and infection}

The lncH19 sequence was obtained from NCBI (no. NR_002196.2). The antisense sequence of lncH19 (5'CGGCAAGAAGCGGGTCTGTTTCTTT-3') was synthesized and cloned into the LV3 vector together with the inverted repeat sequence. The empty vector LV3 was used as a control. The lentivirus solution was prepared by Shanghai Majorbio (China). A549 cells were seeded into 96-well plates at a density of $3 \times 10^{4}$ cells/well. The virus solution was diluted in a $10 \times$ gradient at five different concentrations with DMEM. The supernatant with the culture medium was discarded from each well and supplemented with $100 \mu \mathrm{L}$ of the virus solution, with different concentrations in each well. Saline solution, instead of a virus solution, was used as a control. Cells were incubated at $37^{\circ} \mathrm{C}$ with $5 \% \mathrm{CO}_{2}$ for $24 \mathrm{~h}$. The cell culture supernatant was replaced with $100 \mu \mathrm{L}$ of freshly prepared DMEM. Cells were then incubated for $72 \mathrm{~h}$. RT-PCR was performed to detect lncH19 expression. miRNA inhibitor and the negative control were transfected using lipofectamine 3000 as per the manufacturer's instructions (Thermo Fisher, USA).

\section{ELISA to detect the levels of inflammatory cytokines}

The levels of cytokines in the cell culture supernatant were determined using ELISA kits for TNF- $\alpha$, IL-6, and
IL-8 (Cusabio, Wuhan, China). Briefly, 96-well plates were precoated with TNF- $\alpha$-, IL-6-, and IL-8-specific human antibodies. Human TNF- $\alpha$, IL- 6 , and IL-8 were used to prepare the standard titration curve. Samples and standards were added into 96-well plates and incubated for $120 \mathrm{~min}$ at $37^{\circ} \mathrm{C}$. Then, biotin-labeled antibody was added and the plates were incubated for $60 \mathrm{~min}$ at $37^{\circ} \mathrm{C}$. After washing the plates three times, HRP-avidin was added and the plates were incubated for $60 \mathrm{~min}$ at $37^{\circ} \mathrm{C}$. Following three washes, TMB substrate was added and plates were incubated for $25 \mathrm{~min}$ at $37^{\circ} \mathrm{C}$ and in the dark. A stop solution was added, and the optical density of the samples was measured at $450 \mathrm{~nm}$ via photospectrometry.

\section{RT-PCR}

The expression levels of the mRNAs of inflammatory genes, including IK $\beta-\alpha$, IKK $\beta$, IL-6, IL- 8 and TNF- $\alpha$, lncRNAs, and miRNAs were verified via RT-PCR. The M-MLV Reverse Transcriptase (Promega, USA) was used to synthesize cDNA. PCR reactions were prepared using the GoTaq qPCR Master Mix (Promega, USA) and were performed on the ABI 7500 system (Applied Biosystem, USA). The PCR program was as follows: $95^{\circ} \mathrm{C}$ for $30 \mathrm{~s}$, followed by 40 cycles at $95^{\circ} \mathrm{C}$ for $5 \mathrm{~s}$ and then at $60^{\circ} \mathrm{C}$ for $30 \mathrm{~s}$. The housekeeping genes GAPDH and U6 were used to normalize the expression levels. The primer sequences are shown in Table 1.

\section{Western blotting}

Cells were lysed in 1\% SDS lysis buffer. The BCA assay was used to determine protein concentrations. Proteins were separated using 10\% SDS-PAGE gels. Proteins were then transferred onto polyvinylidene fluoride membranes. Nonfat milk in PBS was used to block the membrane at room temperature for $1 \mathrm{~h}$. The membrane was incubated overnight at $4{ }^{\circ} \mathrm{C}$ with the primary antibody [p-P65 (ab76302; Abcam), P65 (8242; CST), ICAM-1 (sc-107; Santa Cruz), VCAM-1 (sc-13,160; Santa Cruz), and GAPD $\mathrm{H}$ (HC301; Transgen)]. After several washes with PBS, the membranes were incubated with the blocking buffer and secondary antibody coupled to horseradish peroxidase for $2 \mathrm{~h}$ at room temperature. The complexes formed on the membrane were then detected using ECLplus (Amersham Biosciences/GE Healthcare, Velizy, France).

\section{Statistical analysis}

The data are presented as the mean \pm standard deviation (SD), $N=3$. The non-parametric t-test and KruskalWallis test were used to analyze differences between two groups and those among multiple groups, respectively. $P<0.05$ was considered to indicate a statistically significant difference. The IBM SPSS statistics software 22.0 (SPSS Inc., Chicago, IL, USA) was used for statistical analysis. 
Table 1 Primers of mRNA, IncRNA, and miRNA

\begin{tabular}{|c|c|}
\hline Name & sequence $\left(5^{\prime}-3^{\prime}\right)$ \\
\hline H-IL-6-F & ACTCACCTCTTCAGAACGAATTG \\
\hline H-IL-6-R & CCATCTITGGAAGGTTCAGGTTG \\
\hline H-IL-8-F & GACCACACTGCGCCAACAC \\
\hline H-IL-8-R & СТTСТССАСАAСССТСТGCAC \\
\hline TNF-a-F & CTGCACTITGGAGTGATCGG \\
\hline TNF-a-R & GCTTGAGGGTTTGCTACAACAT \\
\hline $\mathrm{H}-\mathrm{I} K K \beta-\mathrm{F}$ & CGATGGCACAATCAGGAAACAGGT \\
\hline$H-\mid$ KK $\beta-R$ & ATTGGGGTGGGTCAGCCTTCTC \\
\hline $\mathrm{H}-\mathrm{IKB}-\mathrm{a}-\mathrm{F}$ & ACACCTTGCCTGTGAGCAGG \\
\hline$H-I K B-a-R$ & AGCACCCAAGGACACCAAAA \\
\hline$\beta$-Actin-F & CATGTACGTTGCTATCCAGGC \\
\hline$\beta$-Actin-R & СTCCTTAATGTCACGCACGAT \\
\hline H-IncMALAT1-F & AAAGTCCGCCATTTGCCAC \\
\hline H-IncMALAT1-R & ACAACTCGCATCACCGGAAT \\
\hline $\mathrm{H}$-IncHotair-F & GCAGTGGGGAACTCTGACTC \\
\hline H-IncHotair-R & TTGAGAGCACCTCCGGGATA \\
\hline $\mathrm{H}-\mathrm{InCH} 19-\mathrm{F}$ & GACATCTGGAGTCTGGCAGG \\
\hline H-IncH19-R & CTGCCACGTCCTGTAACCAA \\
\hline H-IncNeat1-F & GGCAGGTCTAGTTTGGGCAT \\
\hline H-IncNeat1-R & CCTCATCCCTCCCAGTACCA \\
\hline hsa-mir-346-RT & GTCGTATCCAGTGCAGGGTCCGAGGTATTCGCACTGGATACGACCCGCTC \\
\hline hsa-mir-346-F & GGTCTCTGTGTTGGGCGTCT \\
\hline hsa-miR-18a-3p-RT & GTCGTATCCAGTGCAGGGTCCGAGGTATTCGCACTGGATACGACCCAGAA \\
\hline hsa-miR-18a-3p-F & ACTGCCCTAAGTGCTCCTT \\
\hline hsa-mir-324-3p-RT & GTCGTATCCAGTGCAGGGTCCGAGGTATTCGCACTGGATACGACCCAGCA \\
\hline hsa-mir-324-3p -F & CCCACTGCCCCAGGTGCT \\
\hline hsa-miR-146b-5p-RT & GTCGTATCCAGTGCAGGGTCCGAGGTATTCGCACTGGATACGACACCAGA \\
\hline hsa-miR-146b-5p-F & GCCCTGTGGACTCAGTT \\
\hline hsa-miR-18b-5p-RT & GTCGTATCCAGTGCAGGGTCCGAGGTATTCGCACTGGATACGACCTAACT \\
\hline hsa-miR-18b-5p-F & GCGTAAGGTGCATCTAGTGCAG \\
\hline hsa-mir-19a-RT & GTCGTATCCAGTGCAGGGTCCGAGGTATTCGCACTGGATACGACTCAGTT \\
\hline hsa-mir-19a-F & TGTGCAAATCTATGCAAA \\
\hline hsa-miR-19b-3p-RT & GTCGTATCCAGTGCAGGGTCCGAGGTATTCGCACTGGATACGACTCAGTT \\
\hline hsa-miR-19b-3p-F & GTGTGCAAATCCATGCAA \\
\hline Universe-R & GTGCAGGGTCCGAGGT \\
\hline U6-F & CGCTTCGGCAGCACATATAC \\
\hline U6-R & CGAATTGGGTGTCATCCTTG \\
\hline
\end{tabular}

\section{Results}

\section{Dex attenuates the inflammatory response}

To investigate the effects of Dex, we constructed a pulmonary inflammatory cell model using IL-1 $\beta$ and LPS. A549 cells were used for the assay and were treated with $10 \mathrm{ng} / \mathrm{mL}$ IL- $1 \beta$ or $1 \mu \mathrm{g} / \mathrm{mL}$ LPS in DMEM. The cells incubated with the reagents were collected after 8,16 , and
$24 \mathrm{~h}$, and the total RNA was isolated. RT-PCR was conducted to confirm the mRNA expression levels of IK $\beta-\alpha$, IKK $\beta$, IL-6, IL-8, and TNF- $\alpha$. Generally, the results showed that IL-1 $\beta$ performed better against LPS because the mRNA levels of most of the inflammatory cytokines, except for IL-6 and TNF- $\alpha$, were significantly upregulated at $8 \mathrm{~h}$; in addition, the mRNA levels of all other 
cytokines were two- to four-fold greater at $24 \mathrm{~h}$ (Fig. 1a). The secretary cytokines in the cell culture medium, including IL-6, IL-8, and TNF- $\alpha$ were determined via ELIS A. The results were consistent with that of RT-PCR and showed that IL-1 $\beta$ was generally more effective and that an effect can be observed at $8 \mathrm{~h}$ (Fig. 1b). Therefore, we decided to use IL-1 $\beta$ with 24 -h incubation to construct the pulmonary inflammatory cell model.

Following the same principle, we used the cell model to characterize the effects of Dex treatment. We incubated A549 cells with IL-1 $\beta$ and Dex at different concentrations, ranging from $10 \mathrm{nM}$ to $10,000 \mathrm{nM}$, for $24 \mathrm{~h}$. As mentioned above, RT-PCR and ELISA were used to evaluate the effects of Dex. The mRNA expression levels of IK $\beta-\alpha$, IKK $\beta$, IL- 6 , IL- 8 , and TNF- $\alpha$, significantly increased following IL-1 $\beta$ treatment $(P<0.05)$. After adding Dex, the mRNA levels decreased to their baseline levels, indicating that Dex supplementation can attenuate the inflammatory response (Fig. 2a). With respect to the levels of secretary inflammatory cytokines, compared with the control group, the levels of IL-6, IL-8, and TNF- $\alpha$ significantly increased following IL- $1 \beta$ treatment. However, when cells were supplemented with Dex, the levels of cytokines decreased; both 1 and $10 \mu \mathrm{M}$ Dex significantly decreased the levels (Fig. 2b). Taken together, these observations suggest that Dex plays a role in attenuating the inflammatory response.

Verification of the IncRNAs involved in the attenuation of the inflammatory response

Based on our preliminary findings, we targeted four lncRNAs, namely lncMALAT1, lncHotair, lncH19, and lncNeat1, to determine which of these IncRNAs are involved in processes underlying inflammation attenuation [16-20]. RT-PCR was conducted to determine IncRNA levels following treatment with IL-1 $\beta$ and Dex. The results showed that the four candidate lncRNAs were downregulated following IL-1 $\beta$ treatment; however, lncRNA levels increased after Dex supplementation (Fig. 3). In general, lncRNA levels were most clearly observed after treatment with 1 and $10 \mu \mathrm{M}$ Dex $(P<0.05)$. Among the lncRNAs, the level of lncH19 exhibited the highest increase, approximately two-fold, following treatment with 1 and $10 \mu \mathrm{M}$ Dex. Therefore, lncH19 and $1 \mu \mathrm{M}$ Dex were selected for further functional validation.

To verify the functions of $\operatorname{lncH} 19$, the corresponding shRNA was designed and infected into A549 cells using lentivirus. The performance of the specific shRNA was assessed via RT-PCR. LncH19 expression showed a 50\% decrease after transfection with the specific shRNA (Fig. 4a). The cells were then treated with IL-1 $\beta$ and Dex $(1 \mu \mathrm{M})$ to investigate the effect of decreased lncH19 expression. Cell proliferation was assessed via the MTS assay. Treatment with $1 \mu \mathrm{M}$ Dex clearly inhibited cell proliferation, which might only be a side effect. When lncH19 expression was inhibited, cell proliferation increased relative to the group of normal expression of lncH19 (Fig. 4b). We then further validated the functions of $\operatorname{lncH} 19$ via the cell apoptosis assay using flow cytometry. Compared with the percentage of apoptotic cells without Dex treatment, apoptotic cells increased approximately two-fold when Dex was supplemented. Cell apoptosis was inhibited and reduced by $30-50 \%$ when $\operatorname{lncH} 19$ was inhibited under IL-1 $\beta$ and Dex treatment compared with normal expression of lncH19 under IL-1 $\beta$ and Dex treatment (Fig. 4 c \& d 4). Western blotting was conducted to determine the protein level of the genes that might be involved in the inflammatory response, including P65, p-P65, ICAM-1, and VCAM-1. The protein level of P65 did not change. For the rest of

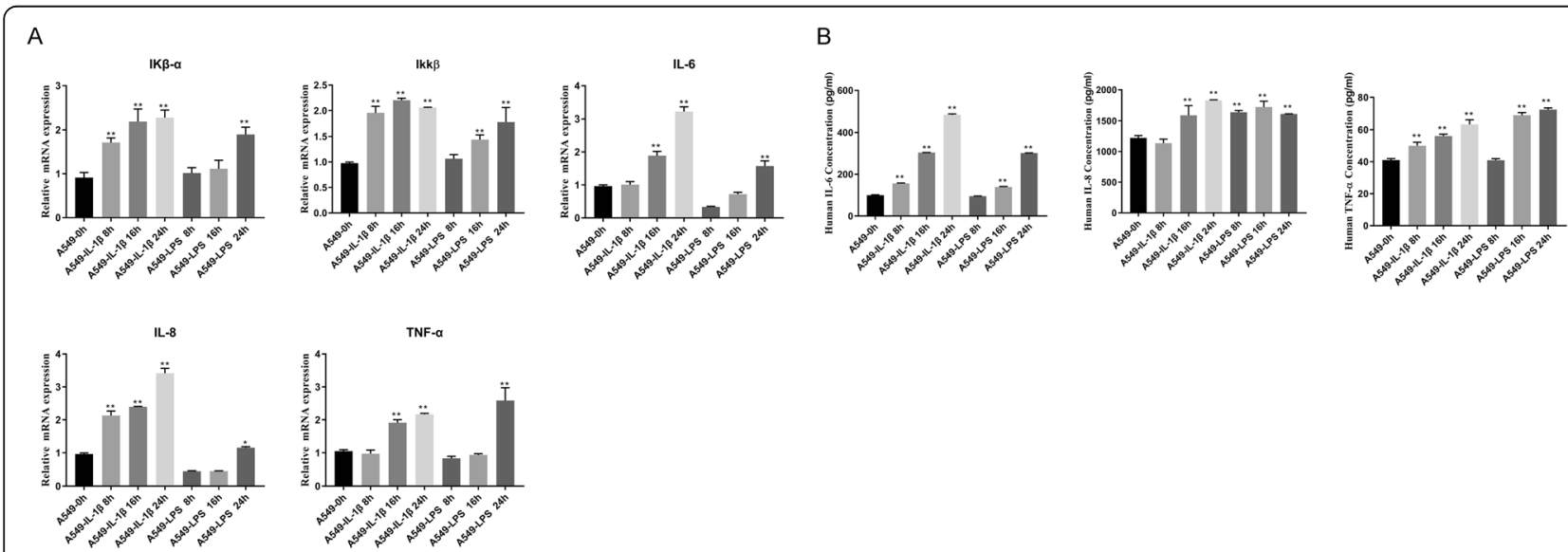

Fig. 1 a pulmonary inflammatory cell model was established by inducing A549 cells with $1 \mathrm{~L}-1 \beta$ ( $10 \mathrm{ng} / \mathrm{mL})$ or LPS ( $1 \mu \mathrm{g} / \mathrm{mL})$ for different time periods. $\mathrm{IL}-1 \beta$ proved to be a more robust inflammatory cell model. A. RT-PCR determination of the corresponding mRNA levels of the inflammatory genes of IKK- $a$, IKK $\beta$, IL-6, IL-8, and TNF-a; GAPDH was used as the housekeeping gene. b. Levels of the inflammatory cytokines IL-6, IL-8, and TNF-a were determined via ELISA. Data are presented as mean \pm SD $N=3$. ${ }^{*} P<0.01$ vs. A549 $0 \mathrm{~h}$. IL-1 $\beta$ : interleukin-1 $\beta$, LPS: lipopolysaccharide 


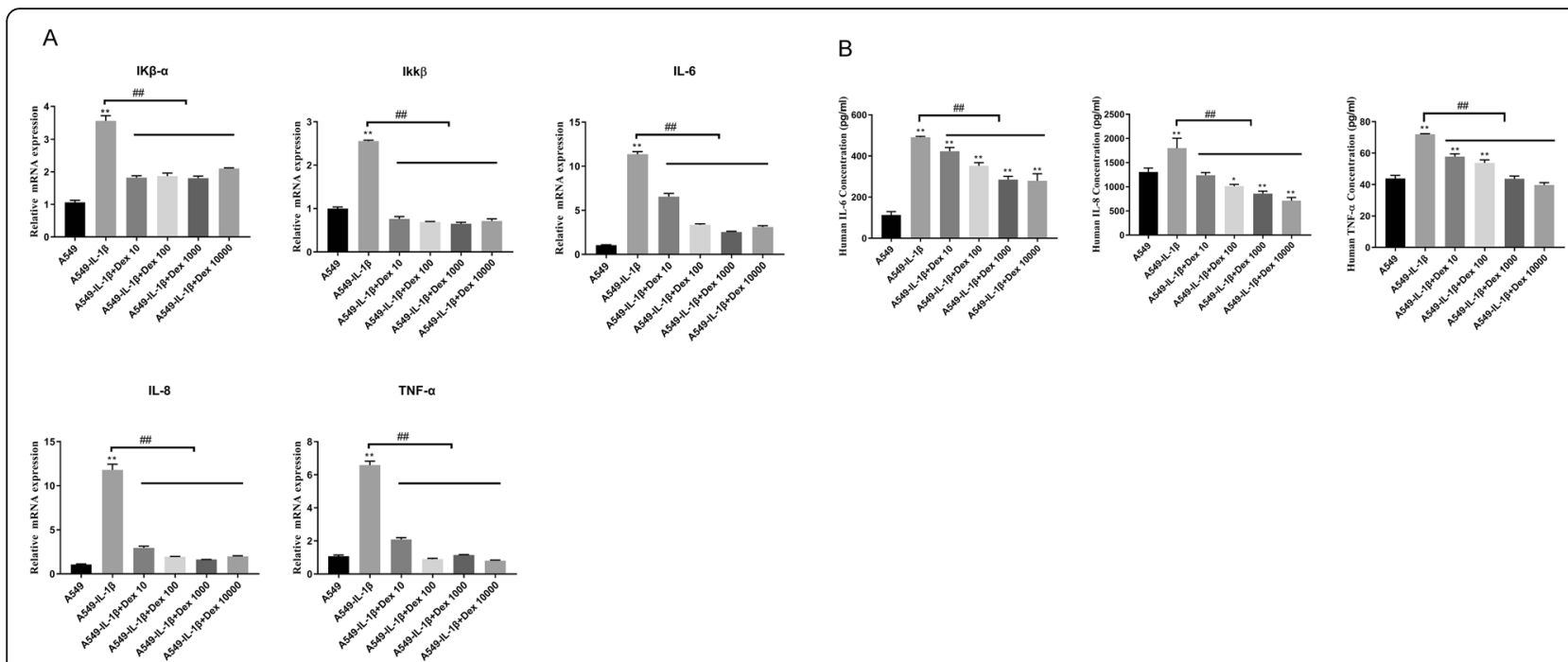

Fig. 2 Different concentrations of Dex $(10 \mathrm{nM}, 100 \mathrm{nM}, 1000 \mathrm{nM}$, and 10,000 nM) can attenuate the inflammatory response induced by IL-1 3 (10 $\mathrm{ng} / \mathrm{mL}$ ). IL-1 $\beta$ and Dex were added at the same time as the stimuli. $\mathbf{a}$. mRNA levels of the inflammatory genes were determined via RT-PCR. $\mathbf{b}$. Levels of the inflammatory cytokines were determined via ELISA. Data are presented as mean \pm SD. $N=3 .{ }^{*} P<0.05$ vs. A549 0 h, ${ }^{* * P}<0.01$ vs. A549 0 h, \#\#P<0.01. Dex: dexamethasone, IL-1 $\beta$ : interleukin-1 $\beta$

the genes, Dex supplementation clearly decreased protein levels; however, lncH19 inhibition could increase protein levels (Fig. 4e). Therefore, given the consistency of these results with those obtained via flow cytometry and the MTS assay, the proteins p-P65, ICAM-1, and VCAM-1 are likely involved in Dex regulation. The cell culture supernatant was then collected and the levels of the inflammatory cytokines, including IL-6, IL-8, and TNF- $\alpha$, were determined. Cytokines decreased in concentration by approximately $50 \%$ following Dex addition. However, lncH19 inhibition increased the levels of inflammatory cytokines (Fig. 4f). Therefore, Dex can attenuate the inflammatory response, and $\mathrm{lncH} 19$ plays an important role in the inflammatory response.

\section{Validation of the candidate miRNAs regulated by IncH19}

Miranda v3.3a was used to predict the target miRNAs of lncH19. The miRNAs are listed in Table 2. Because lncH19 expression was upregulated following Dex addition and because the upregulation of IncRNA tends to result in the downregulation of miRNAs, we searched for downregulated miRNAs following Dex addition. We observed that miR-346, miR-18a-3p, and miR-324-3p were downregulated; therefore, they were chosen for further validation (Fig. 5). The corresponding miRNA inhibitors were designed and transfected into A549 cells. The performance of the inhibitors was assessed via RTPCR. For both miR-18a-3p and miR-324-3p, the corresponding inhibitors clearly decreased the expression of miRNAs by approximately $50 \%$. The inhibitor of miR-324$3 p$ was significantly more effective compared to that of miR-18a-3p (Fig. 6a). Therefore, we further investigated the functions of miR-324-3p and divided the cells into four groups: shNC + IL-1 $\beta+$ Dex + miRNA NC $(\mathrm{NC}+$ miRNA $\mathrm{NC})$, shNC + IL-1 $\beta+$ Dex + miR-324-3p inhibitor $(\mathrm{NC}+$ miR-324-3p inhibitor), shlncH19 + IL-1 $\beta+$ Dex + miRNA NC (shlncH19+miRNA NC), and shlncH19+ IL-1 + Dex + miR-324-3p inhibitor (shlncH19 + miR-324-3p inhibitor). The MTS assay was conducted to assess cell proliferation. Compared with the $\mathrm{NC}+$ miR-324-3p inhibitor group, the cell proliferation of the NC+ miRNA NC group significantly increased at $72 \mathrm{~h}(P<0.05)$. Cell proliferation of the shlncH19+ miRNA NC group increased from an OD value of 1.5 to 2.0 compared with in the $\mathrm{NC}+$ miRNA $\mathrm{NC}$ group. Cell proliferation was lower in the shlncH19 + miR-324-3p inhibitor group than in the shlncH19 + miRNA NC group (Fig. 6b). Therefore, these results suggest that lncH19 expression inhibits cell proliferation and miR-324$3 p$ expression promotes cell proliferation. We also conducted the cell apoptosis assays using flow cytometry to determine the functions of miR-324-3p. IncH19 inhibition reduced the number of apoptotic cells by $\sim 30 \%$; however, miR-324-3p inhibition clearly enhanced cell apoptosis compared with in the NC+ miRNA NC group (Fig. 6c). Compared with the NC+ miRNA NC group, the mRNA levels of IK $\beta-\alpha$, IKK $\beta$, IL-6, IL- 8 , and TNF- $\alpha$ were upregulated when lncH19 was inhibited but downregulated when miR-324-3p was simultaneously inhibited (Fig. 6d). The cell culture supernatant was collected to determine the levels of the cytokines IL-6, IL-8, and TNF- $\alpha$. The levels of the cytokines significantly increased when lncH19 was inhibited by shRNA relative to the $\mathrm{NC}+$ miRNA $\mathrm{NC}$ group. However, the levels of cytokines significantly decreased when the expression of miR-324-3p was 
IncMALAT1

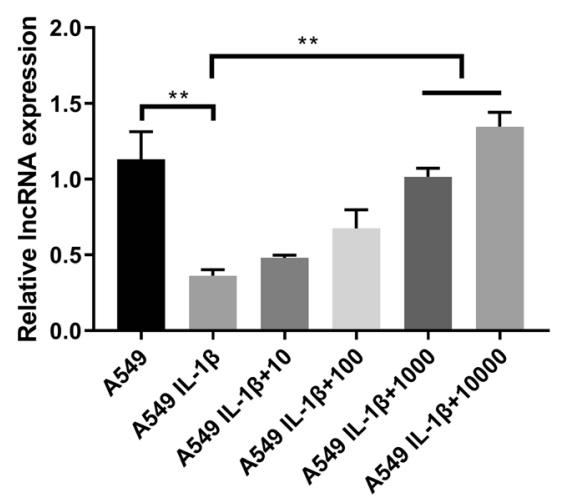

IncH19

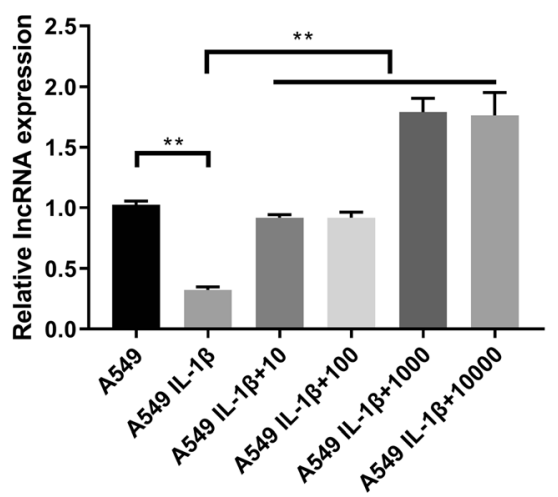

IncHotair

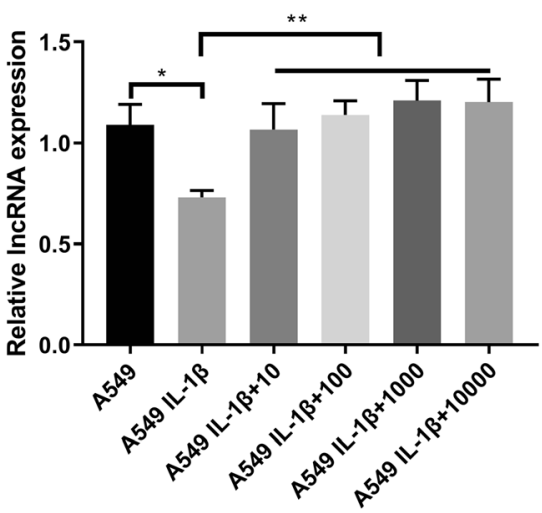

IncNeat1

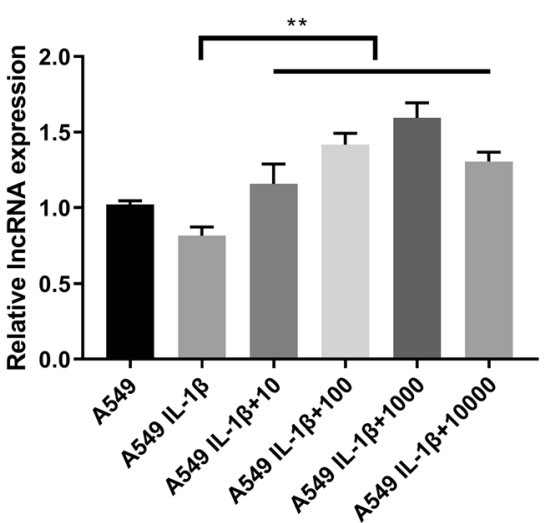

Fig. 3 IncMALAT1, IncHotair, IncH19, and IncNeat1 were downregulated when A549 was treated with IL-1 13 (10 ng/mL) but were upregulated when the inflammatory response was attenuated following the application of Dex $(1 \mu \mathrm{M}) ; \mathrm{IL}-1 \beta$ and Dex were added at the same time as the stimuli. Changes in IncH19 were evident. Data are presented as mean \pm SD. $N=3 .{ }^{*} P<0.05,{ }^{* *} P<0.01$. Dex: dexamethasone, IL-1 $\beta$ : interleukin-1 $\beta$

simultaneously inhibited, indicating that the inflammatory response was suppressed (Fig. 6e). Western blotting was performed to determine the protein levels of inflammatory genes, including p-P65, P65, ICAM-1, and VCAM-1. There was no significant change in the protein level of $\mathrm{P} 65$. IncH19 inhibition increased the protein levels of p-P65, ICAM-1, and VCAM-1 relative to the $\mathrm{NC}+$ miRNA NC group. However, protein levels were decreased when miR-324-3p was downregulated by an inhibitor simultaneously. These findings suggest that miR-324-3p is involved in $\operatorname{lncH} 19$ regulation. lncH19 might target and inhibit miR-324-3p expression and thus regulate inflammation.

\section{Discussion}

In this study, IL-1ß-induced inflammatory A549 cells were attenuated by Dex to aid the study of IncRNAs. Initially, we targeted IncMALAT1, lncHotair, lncH19, and lncNeat1 and evaluated their expression levels. The results showed that $\mathrm{lncH} 19$ was most closely related to the symptoms of inflammation because its expression decreased following IL-1 $\beta$ addition to cells but increased following Dex supplementation. In addition, lncH19 expression negatively correlated with miR-324-3p. We showed that Dex attenuates the inflammatory response by targeting a cascade involving lncH19 and miR-324-3p.

Pulmonary inflammatory diseases, such as asthma, are diseases associated with increase inflammation and loss of bronchial epithelial cells. Increased levels of inflammatory cytokines and cell apoptosis are one of the characteristics of bronchial epithelial cells in patients of pulmonary inflammatory diseases [16-18]. Therefore, drugs with the ability to suppress inflammation and benefit the survival of epithelial cells can improve the outcomes of patients with pulmonary inflammatory disease. In the present study, we used IL-1 $\beta$-induced A549 cells to mimic inflammatory epithelial cells. Based on this inflammatory epithelial cell model, we reveled that $\operatorname{lncH} 19$ is suppressed upon IL-1 $\beta$ induction and is partially restored by Dex, suggesting its role in inflammatory epithelial cells. 


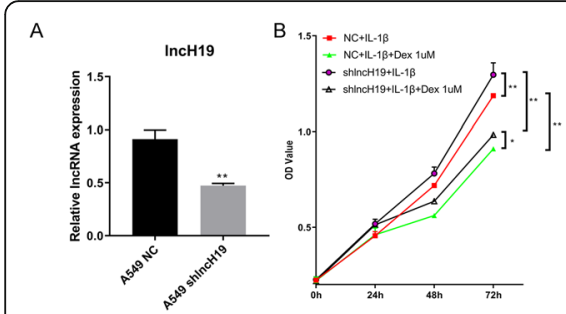

C

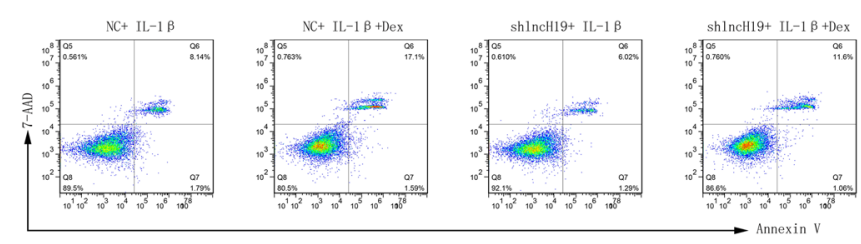

D

$E$

$\mathrm{F}$
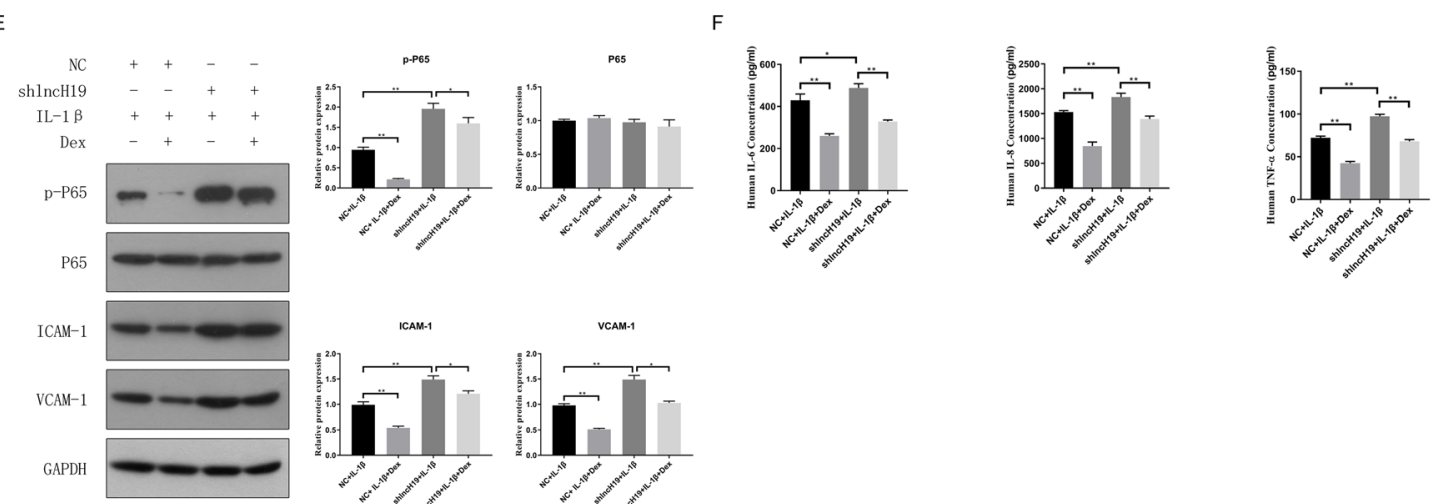

Fig. 4 When IncH19 was inhibited but cells were treated with $\mathrm{IL}-1 \beta(10 \mathrm{ng} / \mathrm{mL})$ with or without Dex $(1 \mu \mathrm{M})$ at the same time, cell proliferation increased, cell apoptosis decreased, and the protein levels of inflammatory genes increased, promoting the phosphorylation of P65, ICAM-1, VCAM-1, and inflammatory cytokines. a. IncH19 expression was reduced, indicating that an IncH19-inhibited cell line was generated. b. Cell proliferation of A549 NC and A549 shlncH19 cells treated with IL-1 $\beta$ with or without Dex. c. Representative cell apoptosis diagram, as measured via flow cytometry. Upper left is the fragment and damaged cells, upper right is the late apoptosis and dead cells, lower left is the normal cells of negative control, and lower right is the early apoptotic cells. The total percent of apoptosis cells was calculated by the sum of cells in the upper right and lower right. $\mathbf{d}$. Percentage of apoptotic cells. e. Western blotting for determining the protein levels of inflammatory genes. $\mathbf{f}$. ELISA for assessing the levels of inflammatory cytokines. Data are presented as mean $\pm S D . N=3 .{ }^{*} P<0.05,{ }^{* *} P<0.01$. Dex: dexamethasone, IL-1 $\beta$ : interleukin-1 $\beta$

LncH19 was discovered in the 11p15.5, H19/IGF2 locus [19]. It is highly expressed in the fetus but begins to be silenced after birth, with its expression restricted to a few tissues, such as the mammary gland, uterus, and adrenal gland [20]. Existing evidence suggests that H19 mutation in mouse zygotes results in prenatal lethality. This indicates that H19 plays an important role in cell growth and development [21]. Therefore, our findings are consistent with those of previous studies that lncH19 can regulate cell proliferation. In addition, we suggested that lncH19 is involved in modulating apoptosis in inflammatory epithelial cells. Notably, lncH19 is associated with the NF- $k B$ pathway and is thus involved in the regulation of cell growth in patients with multiple myeloma [9]. NF- $\mathrm{KB}$ is an important family of transcription factors involved in cell differentiation, apoptosis, and immunity. Activation of the NF- $\mathrm{BB}$ pathway is involved in most cellular processes in cancer transformation, including the inhibition of cell differentiation and cell apoptosis, promotion of cell proliferation, angiogenesis, and potential metastasis [22]. At present, evidence shows that NF- $\mathrm{kB}$ plays a role as a pro-inflammatory mediator in the production of cytokines, chemokines, and cell adhesion molecules in inflammatory cells and

Table 2 Prediction of the target miRNAs of IncH19

\begin{tabular}{lllll}
\hline IncRNA & miRNA & numBindingSitesPredicted & numTargetsPer100bp & specificBindingSitesPredicted \\
\hline NR_002196.2 & hsa-miR-346 & 5 & 0.22 & $252 ; 435 ; 579 ; 887 ; 1114$ \\
NR_002196.2 & hsa-miR-324-3p & 5 & 0.22 & $569 ; 580 ; 723 ; 831 ; 1103$ \\
NR_002196.2 & hsa-miR-18a-3p & 3 & 0.13 & $577 ; 674 ; 828$ \\
NR_002196.2 & hsa-miR-18b-5p & 2 & 0.09 & $137 ; 1667$ \\
NR_002196.2 & hsa-miR-146b-3p & 2 & 0.09 & $257 ; 746$ \\
NR_002196.2 & hsa-miR-19b-3p & 1 & 0.04 & 2023 \\
NR_002196.2 & hsa-miR-19a-3p & 1 & 0.04 & 2034 \\
\hline
\end{tabular}




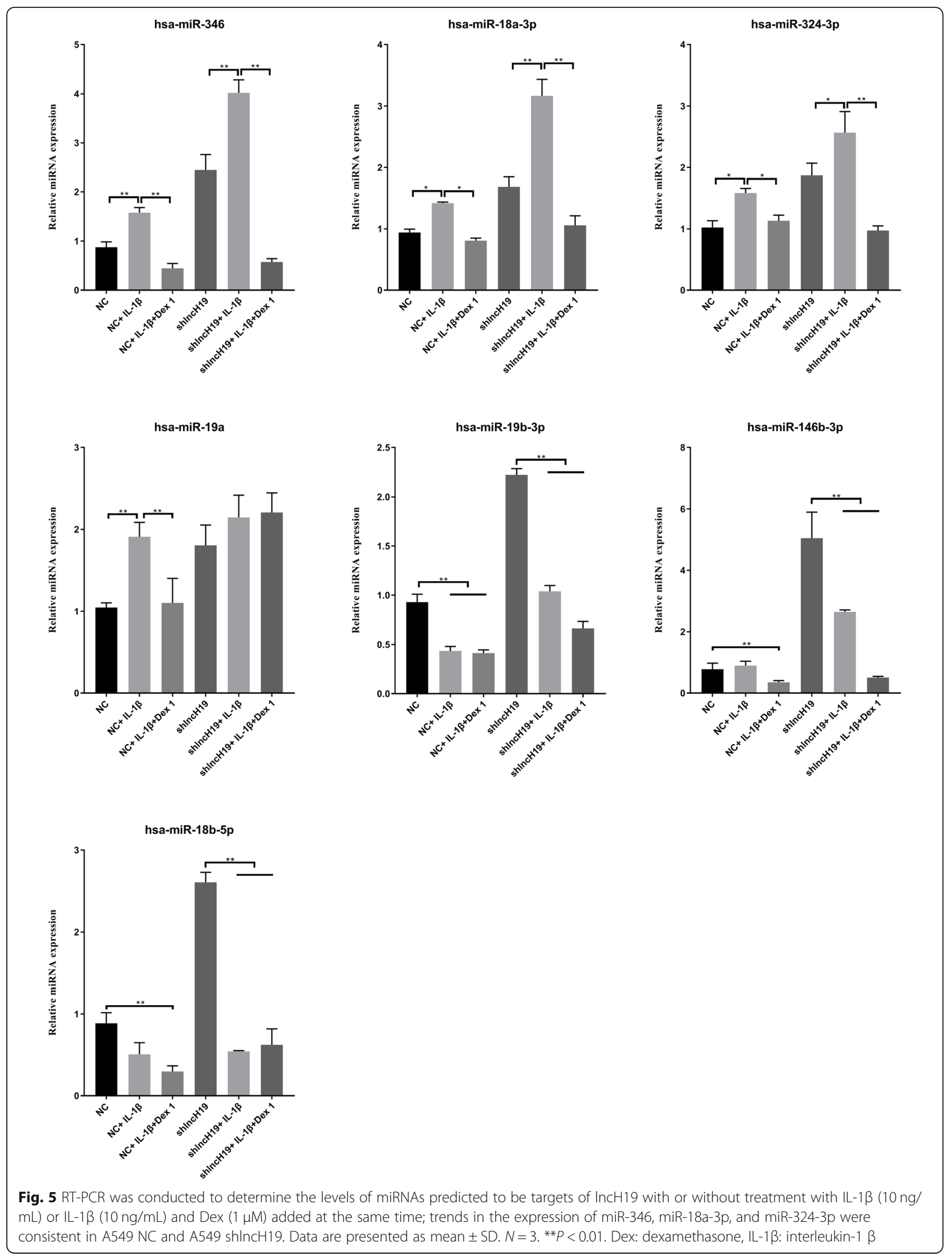




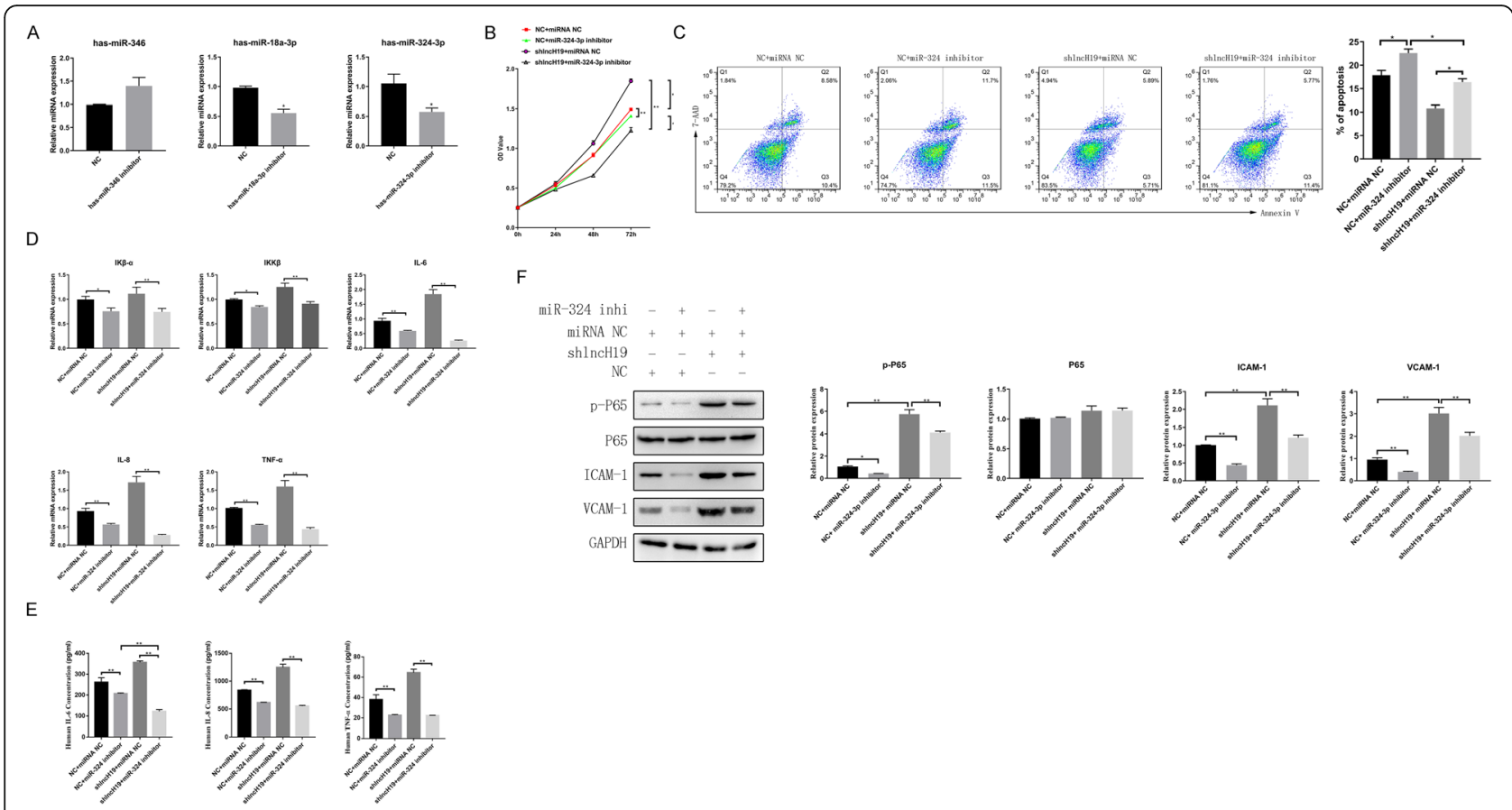

Fig. 6 The attenuation of IncH19 by miR-324-3p was inhibited as the inflammatory response attenuated under treatment with IL-1 $(10 \mathrm{ng} / \mathrm{mL})$ and Dex $(1 \mu \mathrm{M})$ at the same time. a. Levels of the candidate miRNAs, as determined via RT-PCR, for examining the performance of the miRNA inhibitor. b. Cell proliferation was determined using the MTS assay. c. Cell apoptosis was determined via flow cytometry. $\mathbf{d}$. mRNA levels of the inflammatory cytokines. e. ELISA for detecting the levels of the inflammatory cytokines. $\mathbf{f}$. Western blot for detecting the levels of the inflammatory genes. Data are presented as mean $\pm \mathrm{SD} . \mathrm{N}=3$. ${ }^{*} P<0.05$, ${ }^{*} P<0.01$. Dex: dexamethasone. IL-1 $\beta$ : interleukin-1 $\beta ;$ NC + miRNA NC: shNC + IL-1 $\beta$ + Dex + miRNA NC; NC + miR-324-3p inhibitor: shNC + IL-1 $\beta+$ Dex + miR-324-3p inhibitor; shlncH19 + miRNA NC: shlncH19 + IL-1 $\beta+$ Dex + miRNA NC; shlncH19 + miR-324-3p inhibitor: shlncH19 + IL-1 $\beta$ + Dex + miR-324-3p inhibitor

structural cells, such as lung epithelial cells [23]. However, its relationship with lncH19 remains unclear in the context of lung inflammatory epithelial cells. In the present study, we showed that induction of the inflammatory response by IL-1 $\beta$ reduced $\operatorname{lncH} 19$ expression, whereas Dex supplementation, which can attenuate the inflammatory response, significantly increased lncH19 expression. The upregulation of lncH19 expression correlates with the attenuation of the inflammatory response in lung epithelial cells. Taken together, these findings indicate that $\mathrm{lncH} 19$ is involved in the antiinflammatory processes associated with pulmonary inflammatory disease. However, because lncRNAs usually inhibit miRNA targets, lncH19 might not directly target NF- $\mathrm{kB}$. Therefore, we suspect that lncH19 targets and inhibits NF- $\mathrm{KB}$ and possibly other anti-inflammatory factors.

Further studies on lncH19 revealed that the expressions of miR-346, miR-17a-3p, and miR-324-3p were inhibited by $\mathrm{lncH} 19$ overexpression. Following the detection of cell proliferation and cell apoptosis, miR-324-3p inhibition revealed a highly significant correlation between cell proliferation and apoptosis. Therefore, we suspect that lncH19 regulates the inflammatory response by regulating
miR-324-3p. miR-324-3p is a commonly expressed miRNA that regulates the processes underlying cancer. The main target of miR-324-3p is SMAD7. According to $\mathrm{Xu}$ et al., the miR-324-3p/SMAD7 axis plays a significant role in regulating cell growth and apoptosis in patients with nasopharyngeal cancer [24]. The overexpression of SMAD7 is associated with the development of skin, pancreatic, lung, and colon cancer in the processes of cell growth and apoptosis [25]. Previous studies have shown that SMAD7 is associated with the NF-kB pathway and therefore regulates the cell cycle in cancers [26]. Inflammation often changes the expressions of p65, ICAM-1, and VCAM-1; therefore, their expression levels can be used as indicators of the inflammatory response. Previous studies have also shown that p65 is associated with NF- $\mathrm{kB}$ activation [5]. By characterizing the expression of cytokines, we have confirmed that both $\operatorname{lncH} 19$ and miR-324$3 p$ could be important factors involved in regulating the inflammatory response. Therefore, regulation of the inflammatory response might be achieved via the regulation of the SMAD7/NF-kB pathway via a regulatory network between lncH19 and miR-324-3p in which lncH19 targets miR-324-3p. However, this proposed regulatory cascade requires further validation in the future. 
Our results showed that Dex can attenuate the inflammatory response in IL-1 $\beta$-induced inflammatory cells. The lncH19/miR-324-3p axis might play an important role in regulating the inflammatory response, and thus, regulate cell proliferation and cell apoptosis. Future studies should examine additional genes targets of the lncH19/miR-324$3 p$ axis, including SMAD7 and NF- $\kappa B$, to further elucidate the regulatory processes associated with the $\mathrm{lncH} 19 / \mathrm{miR}$ 324-3p axis. Furthermore, the expression of $\operatorname{lncH} 19 / \mathrm{miR}$ 324-3p should be quantified in animal models and patients with pulmonary inflammatory disease before and after the use of corticosteroids. The anti-inflammatory effect of Dex in asthma is regulated by the lncH19/miR324$3 p$ pathways in animal model. The correlation between changes in lncH19 and miR-324-3p expression in specific pulmonary inflammatory diseases, such as asthma, needs to be studied in the future because our hypothesized mechanism is based on an IL-1 $\beta$-induced epithelial cell model. In addition, we can also search for possible ncRNAs using the RNA-seq technology because lncRNAs may also interact with other ncRNAs.

\section{Conclusion}

In summary, we demonstrated for the first time that Dex can attenuate the inflammatory response in inflammatory epithelial cells, an important pathological change closely associated with pulmonary inflammatory diseases, such as asthma, by regulating the $\mathrm{lncH} 19 / \mathrm{miR}-324-3 \mathrm{p}$ cascade.

\section{Acknowledgments}

The authors are grateful to Feng $\mathrm{Xu}$, who provided technical assistance with aspects of this work.

\section{Authors' contributions}

Conceived and designed the experiments: $F X, Y C$, and $C Z$; performed the experiments: CGX and XDL; analyzed the data: FX, CGX, and XDL: contributed toward reagents/materials/analysis tools: FX and ZLH; wrote the paper: $Y C$ and $C Z$; provide revise suggestions: SDH and XJX. All authors read and approved the final manuscript.

\section{Authors' information}

Not available.

\section{Funding}

This study was supported by Subitem Fund for Education (Public Hygiene) of Science \& Technology Fund Project the Technological Invention and Creative Design Program of the Shenzhen Nanshan District (No. 2019018).

\section{Availability of data and materials}

All data generated or analyzed during this study are included in this published article.

\section{Ethics approval and consent to participate}

All procedures were conducted according to the protocols and guidelines approved by Ethics Committee of the Children's Hospital of Chongqing Medical University and were performed following the Declaration of Helsinki.

\section{Consent for publication}

Not applicable.

\section{Competing interests}

The authors declare that they have no competing interests.

\section{Author details}

'Department of Pediatric, Huazhong University of Science and Technology Union Shenzhen Hospital, Shenzhen 518052, China. ${ }^{2}$ Department of Pediatric Intensive Care Unit, Children's Hospital of Chongqing Medical University, No. 136 Zhongshan two road Yuzhong district, Chongqing 400013, China. ${ }^{3}$ Ministry of Education Key Laboratory of Child Development and Disorders, Children's Hospital of Chongqing Medical University, Chongqing 400013, China. ${ }^{4}$ National Clinical Research Center for Child Health and Disorders, Children's Hospital of Chongqing Medical University, Chongqing 400013, China. ${ }^{5}$ China International Science and Technology Cooperation base of Child development and Critical Disorders, Children's Hospital of Chongqing Medical University, Chongqing 400013, China. ${ }^{6}$ Chongqing Key Laboratory of Pediatrics, Children's Hospital of Chongqing Medical University, Chongqing 400013, China. ${ }^{7}$ Department of Neonatology, Huazhong University of Science and Technology Union Shenzhen Hospital, Shenzhen 518052, China.

${ }^{8}$ Traditional Chinese Medicine Department of Rheumatism, Huazhong University of Science and Technology Union Shenzhen Hospital, Shenzhen 518052, China. ${ }^{9}$ Department of Medicine, Research Center of Allergy \& Immunology, Shenzhen University, Shenzhen 518055, China.

Received: 30 January 2020 Accepted: 26 November 2020

Published online: 07 January 2021

\section{References}

1. Reynolds HY. Lung inflammation: role of endogenous chemotactic factors in attracting polymorphonuclear granulocytes. Am Rev Respir Dis. 1983;127: S16-25.

2. Wang YL, Bai C, Li K, Adler KB, Wang X. Role of airway epithelial cells in development of asthma and allergic rhinitis. Respir Med. 2008;102:949-55.

3. Aghasafari $P$, George $U$, Pidaparti R. A review of inflammatory mechanism in airway diseases. Inflamm Res. 2019;68:59-74.

4. Reynolds HY. Lung inflammation: Normal host defense or a complication of some diseases? Annu Rev Med. 1987;38:295-323.

5. Wilson SJ, Wallin A, Della-Cioppa G, Sandström T, Holgate ST. Effects of budesonide and formoterol on NF-KB, adhesion molecules, and cytokines in asthma. Am J Respir Crit Care Med. 2001;164:1047-52.

6. Yan H, Wang Y, Shen S, Wu Z, Wan P. Corticosteroids effects on LPSinduced rat inflammatory keratocyte cell model. PLoS One. 2017;12: e0176639.

7. Spizzo R, Almeida Ml, Colombatti A, Calin GA. Long non-coding RNAs and cancer: a new frontier of translational research. Oncogene. 2012;31:4577-87.

8. Wilusz JE, Sunwoo H, Spector DL. Long noncoding RNAs: functional surprises from the RNA world. Genes Dev. 2009;23:1494-504.

9. Sun Y, Pan J, Zhang N, Wei W, Yu S, Ai L. Knockdown of long non-coding RNA H19 inhibits multiple myeloma cell growth via NF-KB pathway. Sci Rep. 2017;7:1-10.

10. Wu Q, Han L, Yan W, Ji X, Han R, Yang J, et al. MiR-489 inhibits silicainduced pulmonary fibrosis by targeting MyD88 and Smad3 and is negatively regulated by IncRNA CHRF. Sci Rep. 2016;6:30921.

11. Ming X, Duan W, Yi W. Long non-coding RNA NEAT1 predicts elevated chronic obstructive pulmonary disease (COPD) susceptibility and acute exacerbation risk, and correlates with higher disease severity, inflammation, and lower miR-193a in COPD patients. Int J Clin Exp Pathol. 2019;12:2837-48.

12. Han X, Huang S, Xue P, Fu J, Liu L, Zhang C, et al. LncRNA PTPRE-AS1 modulates M2 macrophage activation and inflammatory diseases by epigenetic promotion of PTPRE. Sci Adv. 2019;5:eaax9230.

13. Zhang Y, Willis-Owen SAG, Spiegel S, Lloyd CM, Moffatt MF, Cookson WOCM. The ORMDL3 asthma gene regulates ICAM1 and has multiple effects on cellular inflammation. Am J Respir Crit Care Med. 2019;199: 478-88.

14. King EM, Chivers JE, Rider CF, Minnich A, Giembycz MA, Newton R. Glucocorticoid repression of inflammatory gene expression shows differential responsiveness by transactivation- and Transrepressiondependent mechanisms. PLoS One. 2013;8:e53936.

15. Liu Z, Chen X, Wu Q, Song J, Wang L, Li G. MiR-125b inhibits goblet cell differentiation in allergic airway inflammation by targeting SPDEF. Eur J Pharmacol. 2016;782:14-20.

16. Scheraga RG, Southern BD, Grove LM, OIman MA. The role of transient receptor potential vanilloid 4 in pulmonary inflammatory diseases. Front Immunol. 2017;8:503. 
17. Trautmann A, Krüger K, Akdis M, Müller-Wening D, Akkaya A, Bröcker EB, et al. Apoptosis and loss of adhesion of bronchial epithelial cells in asthma. Int Arch Allergy Immunol. 2005;138:142-50.

18. Mitchell PD, O'Byrne PM. Epithelial-derived cytokines in asthma. Chest. 2017; 151:1338-44.

19. Chu M, Yuan W, Wu S, Wang Z, Mao L, Tian T, et al. Quantitative assessment of polymorphisms in H19 IncRNA and cancer risk: a meta-analysis of 13,392 cases and 18,893 controls. Oncotarget. 2016;7:78631-9.

20. Pachnis V, Belayew A, Tilghman SM. Locus unlinked to a-fetoprotein under the control of the murine raf and Rif genes. Proc Natl Acad Sci U S A. 1984; 81:5523-7.

21. Brunkow ME, Tilghman SM. Ectopic expression of the $\mathrm{H} 19$ gene in mice causes prenatal lethality. Genes Dev. 1991;5:1092-101.

22. Imbert V, Peyron JF. NF-kB in hematological malignancies. Biomedicines. 2017;5:27.

23. Park GY, Lee SH, Hwangbo B, Yim JJ, Lee CT, Kim YW, et al. Proinflammatory cytokine expression through NF-kappaB//kappaB pathway in lung epithelial cells. Tuberc Respir Dis (Seoul). 2000;49:332-42.

24. Xu J, Ai Q, Cao H, Liu Q. MiR-185-3p and miR-324-3p predict radiosensitivity of nasopharyngeal carcinoma and modulate cancer cell growth and apoptosis by targeting SMAD7. Med Sci Monit. 2015;21:2828-36.

25. Briones-Orta MA, Tecalco-Cruz AC, Sosa-Garrocho M, Caligaris C, Macias-Silva M. Inhibitory Smad7: emerging roles in health and disease. Curr Mol Pharmacol. 2012;4:141-53..

26. He Y, Zhang J-M, Xu L-L, Zhu X-L, Jiang $Q$, Jiang $H$, et al. Aberrant TNFAIP3 induces Mesenchymal stem cell impairment via the NF-kb/SMAD7 signaling pathway in immune thrombocytopenia. Blood. 2016;128:364.

\section{Publisher's Note}

Springer Nature remains neutral with regard to jurisdictional claims in published maps and institutional affiliations.

Ready to submit your research? Choose BMC and benefit from:

- fast, convenient online submission

- thorough peer review by experienced researchers in your field

- rapid publication on acceptance

- support for research data, including large and complex data types

- gold Open Access which fosters wider collaboration and increased citations

- maximum visibility for your research: over $100 \mathrm{M}$ website views per year

At $\mathrm{BMC}$, research is always in progress.

Learn more biomedcentral.com/submissions 